\title{
Olaptesed Pegol
}

National Cancer Institute

\section{Source}

National Cancer Institute. Olaptesed Pegol. NCI Thesaurus. Code C99379.

A 45-mer L-stereoisomer RNA olig onucleotide linked to a $40 \mathrm{kDa}$ polyethyleneglycol that targets the small chemokine stromal cell-derived factor 1 (SDF-1 or CXCL12) with potential antineoplastic and hematopoietic stem cell-mobilization activities. SDF-1 targeted agent NOX-A12 specifically binds to SDF-1 thereby preventing the binding of SDF-1 to its receptors CXCR4 and CXCR7 blocking the subsequent receptor activation. This may prevent angiogenesis, tumor cell proliferation, invasion and metastasis and could sensitize tumor cells to chemotherapy. In addition, inhibition of SDF-1/CXCR4 interaction may induce mobilization of hematopoietic cells from the bone marrow into blood. The unique mirror-image configuration of this agent renders it resistant to hydrolysis and does not hybridize with native nucleic acids. Furthermore, this agent does not induce the innate immune response and has shown a favorable immunogenicity profile. 